\title{
Method of Information Technology Enhanced Japanese Vocabulary Learning and Evaluation
}

\author{
https://doi.org/10.3991/ijet.v16i12.22207 \\ Duen-Huang Huang \\ Hsuan Chuang University, Hsinchu City, Taiwan \\ Yuanpei University of Medical Technology, Hsinchu City, Taiwan \\ Hao-En Chueh $(\bowtie)$ \\ Chung Yuan Christian University, Taoyuan City, Taiwan \\ hechueh@cycu .edu.tw \\ Huai-Te Huang, Hong-Fa Ho \\ National Taiwan Normal University, Taipei City, Taiwan \\ Chang-Yi Kao \\ Soochow University, Taipei City, Taiwan
}

\begin{abstract}
Japanese vocabulary proficiency is directly related to Japanese language proficiency, and the learning and evaluation of Japanese vocabulary is vital in Japanese learning. To evaluate the learners' Japanese vocabulary proficiency, in this study, we propose an effective method for evaluating Japanese vocabulary and implement it into a system. To prove the evaluation ability of the proposed method and implemented system, we conducted an experiment involving 80 students from the Japanese Group of the department of applied foreign languages of a senior high school to investigate the effectiveness of the method and system. The results of this study confirmed that (1) the reliability and validity of the proposed Japanese vocabulary evaluation method and system are favorable; and (2) the correlation coefficient between the experimental results and the students' academic performance is higher than 0.80 . Theoretically, the multidimensional Japanese vocabulary quotient model proposed herein can be the basis for Japanese vocabulary detection. Practically, the low-cost and rapid Japanese vocabulary evaluation system developed is applicable to educational evaluation, whereas the technical evaluation method and system for Japanese vocabulary can improve the efficiency and effectiveness in evaluating the Japanese vocabulary of learners.
\end{abstract}

Keywords - Language learning, Japanese vocabulary quotient, technical evaluation system 


\section{Introduction}

Vocabulary is the foundation in developing foreign language skills. If a foreign language learner does not acquire sufficient vocabulary, then he or she will encounter difficulty in understanding sentences and texts. Vocabulary serves as a mediating role in the development of reading, listening, writing, and speaking in language acquisition. Many researchers are interested in factors that affect vocabulary acquisition, and some studies have identified phonological awareness and vocabulary knowledge/memory as important factors affecting children's reading ability [1, 2, $3,4]$. Some researchers have further identified phonological awareness as a factor that affects children's reading ability [5]. Furthermore, some studies indicated that phonological awareness affects children's writing ability $[6,7]$. There is no doubt that vocabulary is an important ability and foundation for foreign language learners.

Most studies suggest that extensive and adequate vocabulary knowledge is a prerequisite for reading fluency $[6,8,9,10,11,12,13]$. People with adequate vocabulary knowledge are better readers $[14,15]$. Conrad [16] investigated the conversion between vocabulary and reading and reported that more spelling practice improves reading ability, more reading improves spelling accuracy, and that spelling has a greater effect on reading than reading has on spelling.

The specific relationship between vocabulary count and reading has been specified in many studies. Hu and Nation [17] argued that non-native English speakers should understand $98 \%$ of the vocabulary in a text, namely text coverage, to achieve better reading. Carver [18] indicates that native English speakers requires 98\% text coverage to achieve better reading. According to Nation [11], identifying 8,000 to 9,000 words is required to achieve a $98 \%$ text coverage, and identifying 6,000 to 7,000 words is the basis for understanding oral English. Other researchers believe that identifying 8,000 words is necessary to achieve a $98 \%$ text coverage [19]. When reading young adult novels, one needs to know at least 5,000 words to achieve $97 \%-98 \%$ text coverage; otherwise, the enjoyment in reading novels will be diminished [20].

To evaluate the learners' vocabulary proficiency, researchers have used several vocabulary tests to measure an individual's vocabulary, such as the vocabulary size test [21], vocabulary levels test $[8,22]$, and Eurocentre vocabulary test [23]. Some researchers used true-false questions [23, 24], whereas others adopted multiple-choice questions [21, 22]. Laufer and Ravenhorst-Kalovski [19] used the vocabulary levels test $[8,22]$ to determine the vocabulary of participants. Ho and Huong [25] proposed a vocabulary quotient (VQ) and employed it to estimate English vocabulary. To evaluate the learners' Japanese vocabulary proficiency, in this study, we used similar methods to propose the VQ of Japanese vocabulary, developed a system, conducted experimental tests, and obtained data for analysis.

The rest of this paper is organized as follows: Section 2 presents related studies about information technology assisted in language learning. Section 3 illustrates the proposed technical evaluation method and system for Japanese vocabulary. Section 4 explains the research method and offers the experimental results. The conclusions are then given in Section 5 . 


\section{Information Technology Assisted in Language Learning}

Innovative information technologies have been used in many studies for language learning $[26,27,28,29]$. In language learning, the most used technologies were corpus, online videos, websites, social networking, intelligent tutoring system, etc.

A corpus is a dataset used by learners to learn language speaking, dialogues, writing documents, etc. Corpus is regarded as an effective technology in language learning due to its rich dictionary resources [30]. Language learning by searching a corpus is a very common way of learning, because learners can find common language examples and formal language expressions in the corpus. Therefore, for learners who are learning vocabulary expression and literary writing, it is especially suitable to use corpus for learning. Li [31] explored whether direct corpus can improve learners' writing collocation ability. This study used experiments conducted between two groups of Chinese graduate students. The experimental results show that students who use the direct corpus have a significant improvement in their writing collocation ability. Ackerley [32] compared the learning performance of students with and without the corpus. The study found that those who used the corpus proved appropriate wording for a wider genre. In addition, the study also found that students who did not use the corpus produced fewer alternate phrases.

There are many video content related to language learning on the Internet. Learners can browse this language learning-related video content on the Internet to learn the language by themselves. Yeh [33] investigated the perceived benefits of learners using a variety of multimedia-assisted learning for video production. The survey results show that most learners believe that multimedia-assisted learning can make it easier for them to understand different cultural literacy, and also easier to understand the meaning of different languages and symbols in different cultures. Arndt and Woore [34] compare the second language vocabulary obtained by users interacting with two different online media (written blog posts and video blogs). They also explored whether there are differences in which aspects of vocabulary knowledge (i.e., spelling, semantics, and grammatical functions) are best learned from these media. The results show that by reading blog posts and watching video blogs, the incidence of accidental vocabulary learning is almost equal. The research results also confirmed that the use of video interactions promoted pragmatics to recall more of the target word's grammatical functions, as well as more awareness and recall of their meanings.

Website refers to various multimedia pages on the Internet. These multimedia pages can provide various languages learning related teaching materials and learning skills [35]. Language learners can browse these multimedia pages with personal computers, tablets, smart phones and other information devices to obtain these language learning-related resources. Lim [36] studied the benefits of using portals to assist students in their interpretation work. The results of the research show that the use of portals for interpretation can not only provide more varied vocabulary combinations, but also complete interpretation tasks quickly and correctly. Ngo [37] investigated whether the use of Web-based technology can be used to improve the oral performance of EFL learners. The survey results show that using Web 2.0 technology as a learning management system helps to create a ubiquitous learning environment, ena- 
bling L2 learners to participate in the language learning process without being restricted by time and space. In addition, Web-Based Language Learning has also been found to reduce the learning anxiety of L2 learners and at the same time make them more proactive language learners.

Language learning through social networking sites is currently one of the most popular learning methods. Social networking sites can help learners create personal learning information [38]. Language learners can build language identities on social networking sites in order to establish a connection with the target language and culture [39, 40], or communicate with other learners on social networking sites [38]. Mompean and Fouz-González [41] tested the results of the research on the effect of pronunciation teaching with Twitter. In this study, the researchers used Twitter to send multiple tweets containing difficult-to-pronounce words to students every day, so that students could learn pronunciation. Research results show that using Twitter for pronunciation teaching is indeed helpful for students' pronunciation learning. Sun et al. [42] believe that most English as a foreign language student lack sufficient opportunities to practice English skills, and social networking sites and mobile learning (especially mobile-assisted language learning) can provide these learners with a new way to practice speaking English in a meaningful way. opportunity. They studied the application of mobile social networking sites in a first-year EFL classroom in China to determine its impact on students' oral skills. They were divided into two classes. One class used mobile social networking sites to learn oral skills, and one class did not use mobile social networking sites to learn oral skills. The results of the experiment show that students who use mobile social networking sites for learning have significantly improved their English fluency. The research results also found that the application of mobile social networking sites for learning can enable learners to speak in English in low-stress and situations.

Intelligent Tutoring System (ITS) is a language learning system that can provide personalized guidance [43]. ITS can automatically record learners' various learning activities, such as the number of logins, learning time, test results, and judge learners' learning effectiveness based on these records. In addition, ITS can also provide materials and teaching methods suitable for learners based on learners' learning effectiveness, so as to enhance learners' learning effectiveness. Troussas et al. [44] proposes an intelligent tutoring system for learning English and French concepts. The system incorporates a novel model that uses machine learning for error diagnosis. The model uses two algorithmic techniques, especially approximate string matching and string meaning similarity, to diagnose spelling errors, errors in the use of tense, errors in the use of auxiliary verbs, and confusion caused by simultaneous language tuition error. The model used for error diagnosis is used by the fuzzy logic model, which takes the results of the first or knowledge dependency relationship between different domain concepts of the learning materials as input, and dynamically determines the learning content suitable for delivery to the learning content. Baker et al. [45] studied the prospects, usability and feasibility of Intelligent Tutoring System to improve the vocabulary and language skills of second-grade Latinx English learners in scientific and social studies. The research results show that compared with the words taught, the 
students who use ITS have a significant improvement in their vocabulary knowledge. The results also show that most students like to use ITS and learn new words.

\section{Technical evaluation method and system for Japanese vocabulary}

In this study, the key performance indicator concept in management science was applied to Japanese as a foreign language (JFL) and the Japanese vocabulary quotient (JVQ) was proposed to provide learners and instructors with a set of objective quantitative indicators, benefitting both theoretical and practical teaching and learning (Ho \& Huong, 2011).

The JVQ is a set of four quotients obtained from four standardized Japanese vocabulary tests.

Definition 1: The JVQ is expressed as JVQ (p, m, L, t, z) $=\{$ JVQi $1<\mathrm{i}<\mathrm{d}\}$, where $p$ is the participant; $m$ is the native language of $p$, which was set as Chinese in this study; L is the set of target Japanese vocabulary, e.g., 800 Level 5 Japanese vocabulary exists; $t$ is the date on which the test was performed; $z$ is the number of questions in each test, which is a positive integer; JVQi is the number of correct answers in test model i divided by $z$; $d$ is the type of test, which was set as 4 in this study.

In this study, a uniform distribution random function was used to select Japanese vocabulary materials in $\mathrm{L}$ for each test. The definition above is applicable to any human natural language, both L1L1 and L1L2. The test models for different languages vary. The JVQ for each individual is a time-varying function, where a larger $\mathrm{z}$ indicates higher accuracy.

Four test models $(\mathrm{d}=4)$ were proposed in this study, which are described as Table 1 :

Table 1. Japanese vocabulary test models

\begin{tabular}{|c|l|}
\hline Test model & \multicolumn{1}{|c|}{ Description } \\
\hline Test model 1 & $\begin{array}{l}\text { Given } \mathrm{Cp}(\mathrm{Jt}) \text { with } \mathrm{V}(\mathrm{Jt}) . \\
\text { Examinee is asked to key-in the target Japanese vocabulary Jt. }\end{array}$ \\
\hline Test model 3 & $\begin{array}{l}\text { Given } \mathrm{Jt} \text { and } 4 \text { choices } \mathrm{Cp}(\mathrm{Jt}), \mathrm{Cq}, \mathrm{Cr} \text { and } \mathrm{Cs} \text { in random sequence. } \mathrm{Cp}(\mathrm{Jt}) \text { is the best } \\
\text { choice, and } \mathrm{Cq}, \mathrm{Cr} \text { and } \mathrm{Cs} \text { are wrong choices. } \\
\text { Examinee is asked to choose the best choice. }\end{array}$ \\
\hline Test model 3 & $\begin{array}{l}\text { Given } \mathrm{V}(\mathrm{Jt}) \text { and } 4 \text { choices } \mathrm{Cp}(\mathrm{Jt}), \mathrm{Cq}, \mathrm{Cr} \text { and } \mathrm{Cs} \text { in random sequence. Cp (Jt) is the best } \\
\text { choice which matches the given } \mathrm{V}(\mathrm{Jt}), \text { and } \mathrm{Cq}, \mathrm{Cr} \text { and } \mathrm{Cs} \text { are wrong choices. } \\
\text { Examinee is asked to choose the best choice. }\end{array}$ \\
\hline Test model 4 & $\begin{array}{l}\text { Given } \mathrm{Cp}(\mathrm{Jt}) \text { and } 4 \text { choices } \mathrm{V}(\mathrm{Jt}), \mathrm{Vq}, \mathrm{Vr} \text { and } \mathrm{Vs} \text { in random sequence. } \mathrm{V}(\mathrm{Jt}) \text { is the best } \\
\text { choice which matches the given } \mathrm{Cp}(\mathrm{Jt}), \text { and } \mathrm{Vq}, \mathrm{Vr} \text { and } \mathrm{Vs} \text { are wrong choices. } \\
\text { Examinee is asked to choose the best choice. }\end{array}$ \\
\hline
\end{tabular}

In Table 1, V () and V represent the pronunciation of a Japanese word, Jt the target Japanese word, and $\mathrm{Cp}()$ and $\mathrm{C}$ the Chinese interpretation of a Japanese word.

According to Table 1, for JFL learners, the JVQ comprises four quotients, which are expressed as follows: 


$$
\text { JVQ(p, m, L, t, z) }=<\text { JVQ1, JVQ2, JVQ3, JVQ4 }>\text {, where } 0 \leq \mathrm{JVQi} \leq 1 \text {. }
$$

Definition 2: Estimated Japanese vocabulary according to JVQ, $|\mathrm{L}|$ denotes the number of Japanese vocabulary in $\mathrm{L}$. The four estimated Japanese vocabularies can be calculated using the following equation:

$$
\mathrm{EJVQi}=|\mathrm{L}| * J V Q \mathrm{i}, 1<\mathrm{i}<4 .
$$

To calculate the four estimated Japanese vocabularies for an individual, the first step is to use the software developed in this study for testing and obtain the data in Equation (1); subsequently, Equation (2) is to be used to calculate the four estimated values.

Based on the four tests presented in Table 1, we adopted Adobe's Director 11.5 to develop a soft-question system for the JVQ. The screens of the four tests (writing, reading, basic listening, advanced listening) are shown in Fig. 1 to Fig.4.

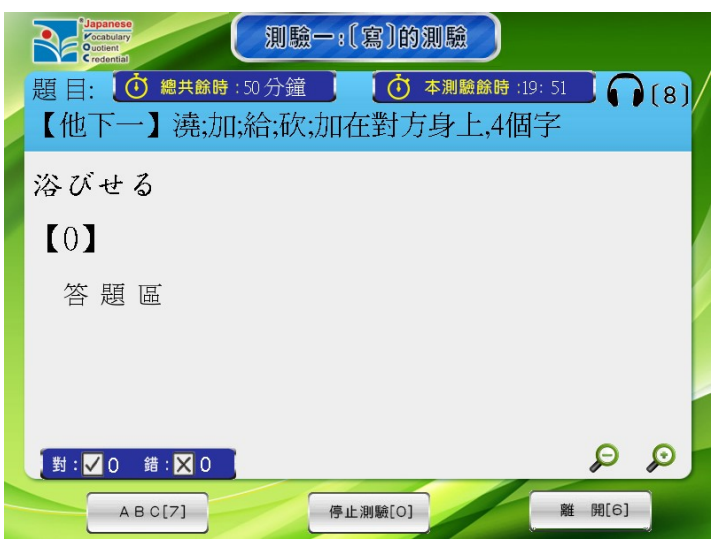

Fig. 1. JVQ screens of writing test

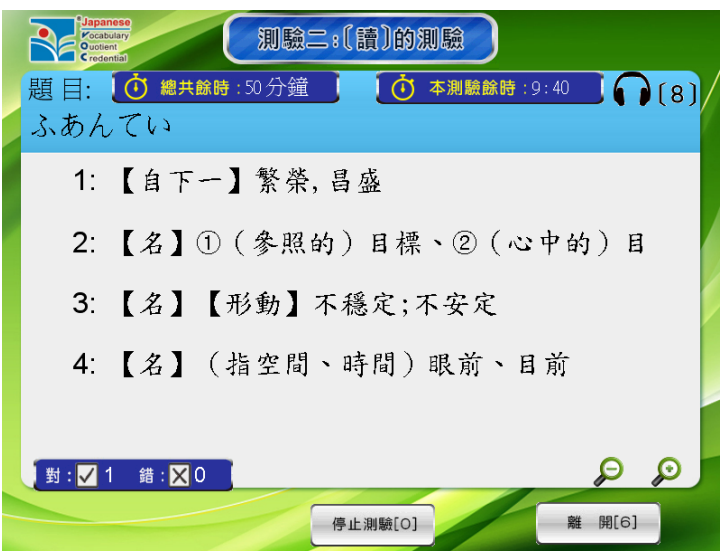

Fig. 2. JVQ screens of reading test 


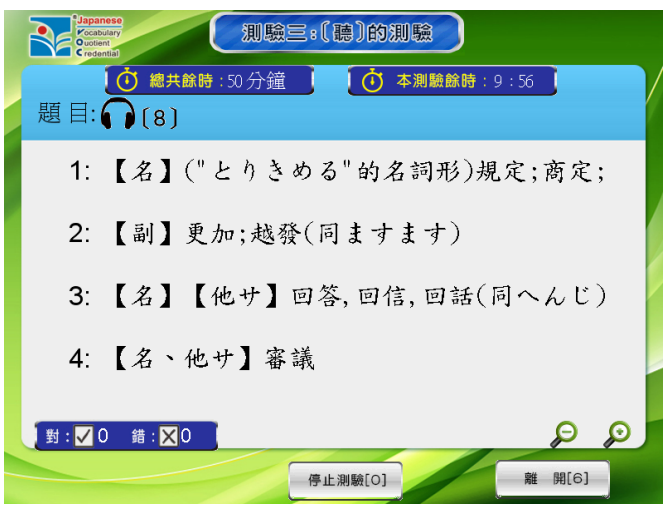

Fig. 3. JVQ screens of basic listening test

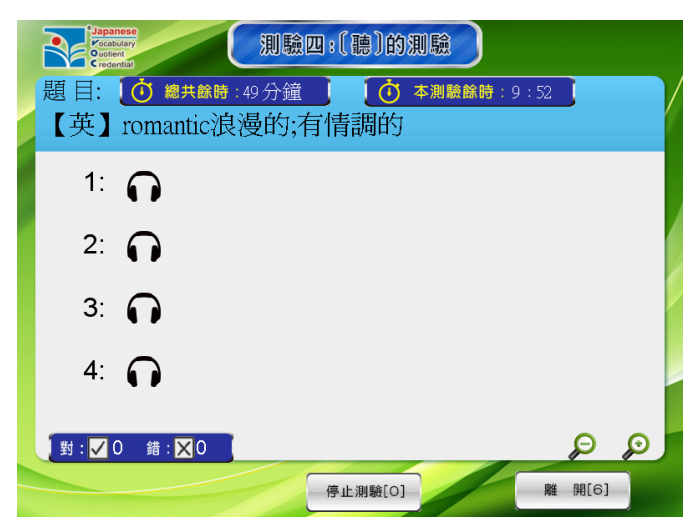

Fig. 4. JVQ screens of advanced listening test

\section{$4 \quad$ Research Method and Experimental Results}

To calculate the four estimated Japanese vocabularies for an individual, the first step is to use the software developed in this study for testing and obtain the data in Equation (1); subsequently, Equation (2) is to be used to calculate the four estimated values.

\subsection{Participants}

The participants of this study were 80 second-year high school students $(\mathrm{N}=80)$ from the Japanese Group of the department of applied foreign languages of Hsinchu Kuang-Fu senior high school in Taiwan, with an average age of 17.45 years $(\mathrm{SD}=$ 0.34 ), all of whom had studied Japanese for one year. 


\subsection{Materials}

Level 4 Japanese vocabulary comprising 1,500 Japanese words, which was appropriate for the participants, was selected. Each word had the correct and appropriate Chinese translation, pronunciation, tone, and Chinese characters. All questions were presented using computer software. Each test comprised 100 questions that were selected randomly and never repeated. The question theory was based on item response theory, and the questions varied for each participant. To avoid the slow input speed of the computer keyboard causing Test 1 to be affected by the key-in speed, only Tests 2,3 , and 4 , which comprised single-choice questions, were performed in the experiment.

\subsection{Experimental design}

The experiment performed was a single-group, single-shot test. Dependent variables included Japanese first-grade results for the second semester and three JVQ test scores. Descriptive statistics and correlation analysis were used to test the hypothesis.

\subsection{Procedure}

First, the participants entered a computer classroom to learn how to use the test software; therein, they registered for an account and were provided with a set of headphones. Subsequently, the participants were asked to familiarize themselves with the software tools until they can use them easily and correctly. The formal test was followed by three types of questions, each comprising 100 questions. The participants provided their answers by clicking on a mouse. The entire experiment lasted approximately $30 \mathrm{~min}$.

\subsection{Tools and data collection}

Japanese vocabulary test (Level 4) software, account number, score server, headphones, and two multimedia computer classrooms with 100 sets were used in the experiment. All test scores were collected automatically by the software. Eleven participants who were unable to complete the test because they left at their own volition or because of computer crashes were eliminated; hence, only 69 valid samples remained.

\subsection{Data analysis}

Table 2 shows the descriptive statistics and reveals that the variances of the four scores were similar. Table 3 shows the correlation analysis between the last semester grades and each of JVQ2, JVQ3, and JVQ4. 
Table 2. Descriptive statistics

\begin{tabular}{|l|c|c|c|c|}
\hline \multicolumn{1}{|c|}{ Statistics } & Last semester Japanese grades & JVQ2 & JVQ3 & JVQ4 \\
\hline Mean & 74.68 & 63.14 & 63.96 & 63.04 \\
\hline Standard error & 2.20 & 2.20 & 2.09 & 2.35 \\
\hline Median & 76 & 60 & 64 & 65 \\
\hline Mode & 93 & 53 & 64 & 73 \\
\hline Standard deviation & 18.25 & 18.31 & 17.33 & 19.55 \\
\hline Variation & 333.01 & 335.27 & 300.40 & 382.25 \\
\hline Kurtosis & -0.58 & -0.81 & -0.87 & -0.60 \\
\hline Skewness & -0.61 & -0.01 & -0.03 & -0.39 \\
\hline Minimum & 30 & 23 & 26 & 12 \\
\hline Maximum & 98 & 97 & 96 & 93 \\
\hline Number & 69 & 69 & 69 & 69 \\
\hline Kth largest value (1) & 98 & 97 & 96 & 93 \\
\hline Kth smallest value (1) & 30 & 23 & 26 & 12 \\
\hline Reliability (95.0\%) & 4.38 & 4.40 & 4.16 & 4.70 \\
\hline
\end{tabular}

Table 3. Correlation analysis (last semester Japanese grades)

\begin{tabular}{|l|c|c|c|}
\hline & JVQ2 & JVQ3 & JVQ4 \\
\hline Last semester Japanese grades & 0.8486 & 0.8499 & 0.8483 \\
\hline
\end{tabular}

\section{Conclusion}

EFL students often encounter the problem of insufficient vocabulary. Some studies believe that Japanese vocabulary is one of the most critical parts while teaching and learning Japanese. EFL teachers and students need an effective way to manage vocabulary. In order to manage vocabulary, low-cost feasible evaluation methods, objective quantification, vocabulary estimation methods and evaluation systems are needed.

This study applies the concept of KPI (Key Performance Indicator) from management science to the learning and teaching of EFL vocabulary, and proposes a Japanese vocabulary quotient (JVQ) with four models as KPI.

Besides a set of VQ for the Japanese vocabulary test, a multimedia Japanese vocabulary evaluation system was also developed in this study. The experimental results of three tests performed showed a correlation coefficient of 0.85 with the teachers' normal objective evaluation results. This indicated that the reliability, validity, and discrimination of the method and system in this study were similar to the teacher's normal objective evaluation results. Based on the JVQ data, the number of Japanese vocabulary in the entire class was estimated to be approximately $0.63 \times 1500=945$. In addition, the number of Japanese vocabulary per participant can be estimated. Hence, this quotient and system can be used for both theoretical and practical evaluations.

The JVQ with four test models proposed in this study cannot cover oral ability, because the accuracy of Japanese vocabulary speech recognition technology is far below the minimum requirement. However, if the Japanese vocabulary speech recognition 
technology is mature in the future, the oral ability of the vocabulary should be added to the JVQ.

\section{References}

[1] Verhoeven, L. (1990). Acquisition of reading in a second language. Reading Research Quarterly, 25: 90-114. https://doi.org/10.2307/747596

[2] Gathercole, S. E., Willis, C. S., Emslie, H., Baddeley, A. D. (1992). Phonological memory and vocabulary development during the early school years: a longitudinal study. Developmental Psychology, 28(5): 887-898. https://doi.org/10.1037/0012-1649.28.5.887

[3] Chiappe, P., Siegel, L. S., Wade-Woolley, L. (2002). Linguistic diversity and the development of reading skills: a longitudinal study. Scientific Studies of Reading, 6(4): 369400. https://doi.org/10.1207/s1532799xssr0604 04

[4] Jongejan, W., Verhoeven, L., Siegel, L. S. (2007). Predictors of reading and spelling abilities in first- and second-language learners. Journal of Educational Psychology, 99(4): 835851. https://doi.org/10.1037/0022-0663.99.4.835

[5] [5] Hulme, C., Snowling, M., Caravolas, M., Carroll, J. (2005). Phonological skills are (probably) one cause of success in learning to read: a comment on Castles and Coltheart. Scientific Studies of Reading, 9(4): 351-365. https://doi.org/10.1207/s1532799xssr0904 2

[6] Caravolas, M., Hulme, C., Snowling, M. J. (2001). The foundations of spelling ability: evidence from a 3-year longitudinal study. Journal of Memory and Language, 45(4): 751774. https://doi.org/10.1006/jmla.2000.2785

[7] Landerl, K., Wimmer, H. (2008). Development of word reading fluency and spelling in a consistent orthography: an 8-year follow up. Journal of Educational Psychology, 100(1): 150-161. https://doi.org/10.1037/0022-0663.100.1.150

[8] Laufer, B. (1992). Reading in a foreign language: how does L2 lexical knowledge interact with the reader's general academic ability? Journal of Research in Reading, 15(2): 95-103. https://doi.org/10.1111/j.1467-9817.1992.tb00025.x

[9] Qian, D. D. (1999). Assessment the roles of depth and breadth of vocabulary knowledge in reading comprehension. The Canadian Modern Language Review, 56(2): 282-308. https://doi.org/10.3138/cmlr.56.2.282

[10] Qian, D. D. (2002). Investigating the relationship between vocabulary knowledge and academic reading performance: an assessment perspective. Language Learning, 52(3): 513536. https://doi.org/10.1111/1467-9922.00193

[11] Nation, I. S. P. (2006). How large a vocabulary is needed for reading and listening? The Canadian Modern Language Review, 63(1): 59-82. https://doi.org/10. 3138/cmlr.63.1.59

[12] Braze, D., Tabor, W., Shankweiler, D. P., Mencl, W. E. (2007). Speaking up for vocabulary: reading skill differences in young adults. Journal of Learning Disabilities, 40(3): 226243. https://doi.org/10.1177/00222194070400030401

[13] Shiotsu, T., Weir, C. J. (2007). The relative significance of syntactic knowledge and vocabulary breadth in the prediction of reading comprehension test performance. Language Testing, 24(1): 99-128. https://doi.org/10.1177/0265532207071513

[14] Lervag, A., Aukrust, V. G. (2010). Vocabulary knowledge is a critical determinant of the difference in reading comprehension growth between first and second language learners. Journal of Child Psychology and Psychiatry, 51(5): 612-620.https://doi.org/10.1111/ j.1469-7610.2009.02185.x 
[15] Rashidi, N., Khosravi, N. (2010). Assessing the role of depth and breadth of vocabulary knowledge in reading comprehension of Iranian EFL learners. Pan-Pacific Association of Applied Linguistics, 14(1): 81-108.

[16] Conrad, N. J. (2008). From reading to spelling and spelling to reading: transfer goes both ways. Journal of Educational Psychology, 100(4): 869-878. https://doi.org/10. $\underline{1037 / \mathrm{a} 0012544}$

[17] Hu, M., Nation, I. S. P. (2000). Unknown vocabulary density and reading comprehension. Reading in a Foreign Language, 13(1): 403-430.

[18] Carver, R. P. (1994). Percentage of unknown vocabulary words in text as a function of the relative difficulty of the text: implications for instruction. Journal of Reading Behavior, 26(4): 413-437. https://doi.org/10.1080/10862969409547861

[19] Laufer, B., Ravenhorst-Kalovski, G. C. (2010). Lexical threshold revisited: lexical text coverage, learners' vocabulary size and reading comprehension. Reading in a Foreign Language, 22(1): 15-30. https://doi.org/10.5353/th b3195924

[20] Hirsh, D., Nation, P. (1992). What vocabulary size is needed to read unsimplified texts for pleasure? Reading in a Foreign Language, 8(2): 689-696. https://doi.org/10.26686/ wgtn. 12560417

[21] Beglar, D. (2010). A Rasch-based validation of the vocabulary size test. Language Testing, 27(1): 101-118. https://doi.org/10.1177/0265532209340194

[22] Nation, I. S. P. (1990). Teaching and learning vocabulary, New York: Newbury House.

[23] Meara, P., Buxton, B. (1987). An alternative to multiple choice vocabulary tests. Language Testing. 4: 142-154. https://doi.org/10.1177/026553228700400202

[24] Mochida, A., Harrington, M. (2006). The yes/no test as a measure of receptive vocabulary knowledge. Language Testing, 23(1): 73-98. https://doi.org/10.1191/02655322061t321oa

[25] Ho, H. F., Huong, C. (2011). A multiple aspects quantitative indicator for ability of English vocabulary: vocabulary quotient. Journal of Educational Technology Development and Exchange, 4(1): 15-22. https://doi.org/10.18785/jetde.0401.02

[26] Shadiev, R., Yang, M. (2020). Review of Studies on Technology-Enhanced Language Learning and Teaching. Sustainability, 12(2): 524. https://doi.org/10.3390/su12020524

[27] Jin, X. (2020). Application of Computer in Online Teaching of Professional Courses. International Journal of Emerging Technologies in Learning, 15(19): 53-65.

[28] Aprianto, E., Purwati, O., Anam, S. (2020). Multimedia-Assisted Learning in a Flipped Classroom: A Case Study of Autonomous Learning on EFL University Students. International Journal of Emerging Technologies in Learning, 15(24): 114-127. https://doi.org/10. 3991/ijet.v15i24.14017

[29] Murzo, Y., Chuvileva, N. (2021). Use of Information Technologies in Developing Foreign Language Competence for Professional Interaction of Undergraduate and Postgraduate Students Specializing in Mineral Resources. International Journal of Emerging Technologies in Learning, 16(3): 144-153. https://doi.org/10.3991/ijet. v16i03.17875

[30] Frankenberg-Garcia, A., Lew, R., Roberts, J. C., Rees, G. P., Sharma, N. (2019). Developing a writing assistant to help EAP writers with collocations in real time. ReCALL, 31(1): 23-39. https://doi.org/10.1017/s0958344018000150

[31] Li, S. (2017). Using corpora to develop learners' collocational competence. Language Learning \& Technology, 21(3): 153-171.

[32] Ackerley, K. (2017). Effects of corpus-based instruction on phraseology in learner English. Language Learning \& Technology, 21(3), 195-216.

[33] Yeh, H. C. (2018). Exploring the perceived benefits of the process of multimodal video making in developing multiliteracies. Language Learning \& Technology, 22(3): 28-37. 
[34] Arndt, H. L., Woore, R. (2018). Vocabulary learning from watching YouTube videos and reading blog posts. Language Learning \& Technology, 22(1): 124-142.

[35] Shen, H., Yuan, Y., Ewing, R. (2015). English learning websites and digital resources from the perspective of Chinese university EFL practitioners. ReCALL, 27(2): 156-176. https://doi.org/10.1017/s0958344014000263

[36] Lim, L. (2014). Engaging student interpreters in vocabulary building: Web search with computer workbench. ReCALL, 26(3): 355-373. https://doi.org/10.1017/s095834401400 $\underline{0123}$

[37] Ngo, C.-L. (2018). Web-Based Language Learning (WBLL) for Enhancing L2 Speaking Performance: A Review. Advances in Language and Literary Studies, 9(4): 143-152. https://doi.org/10.7575/aiac.alls.v.9n.4p.143

[38] Maier, C., Laumer, S., Eckhardt, A., \& Weitzel, T. (2015). Giving too much social support: Social overload on social networking sites. European Journal of Information Systems, 24(5): 447-464. https://doi.org/10.1057/ejis.2014.3

[39] Blattner, G., Fiori, M. (2011). Virtual social network communities: An investigation of language learners' development of sociopragmatic awareness and multiliteracy skills. CALICO Journal, 29(1): 24-43. https://doi.org/10.11139/cj.29.1.24-43

[40] Klimanova, L., Dembovskaya, S. (2013). L2 identity, discourse, and social networking in Russian. Language Learning \& Technology, 17(1): 69-88.

[41] Mompean, J. A., Fouz-González, J. (2016). Twitter-based EFL pronunciation instruction. Language Learning \& Technology, 20(1): 166-190.

[42] Sun, Z., Lin, C.-H., You, J., Shen, H. J., Qi, S., Luo, L. (2017). Improving the Englishspeaking skills of young learners through mobile social networking. Computer Assisted Language Learning, 30(3-4): 304-324.https://doi.org/10.1080/09588221. 2017.1308384

[43] Malekzadeh, M., Mustafa, M. B., Lahsasna, A. (2015). A review of emotion regulation in intelligent tutoring systems. Educational Technology \& Society, 18(4): 435-445.

[44] Troussas, C., Chrysafiadi, K., Virvou, M. (2018). Machine Learning and Fuzzy Logic Techniques for Personalized Tutoring of Foreign Languages. Lecture Notes in Computer Science, 10948: 358-362. https://doi.org/10.1007/978-3-319-93846-2_67

[45] Baker, D. L., Ma, H., Polanco, P., Conry, J. M., Kamata, A., Otaiba, S. A., Ward, W., Cole, R. (2020). Development and promise of a vocabulary intelligent tutoring system for second-grade Latinx English learners. Journal of Research on Technology in Education, Advance online publication. https://doi.org/10.1080/15391523.2020.1762519

\section{$7 \quad$ Authors}

Duen-Huang Huang is an assistant professor of the Department of Information Management at Hsuan Chuang University and at Yuanpei University of Medical Technology, Hsinchu City, Taiwan. He received his Ph.D. in Industrial Education from National Taiwan Normal University, Taiwan in 2014. His research areas include e-learning, digital transformation, and fuzzy mathematics.

Hao-En Chueh is an assistant professor of the Department of Information Management at Chung Yuan Christian University, Taoyuan City, Taiwan. He received his $\mathrm{Ph} . \mathrm{D}$. in Computer Science and Information Engineering from Tamkang University, Taiwan in 2007. His research areas include data dining, artificial intelligence, medical informatics. Email: hechueh@cycu.edu.tw 
Huai-Te Huang, a graduate student of Industrial Education at National Taiwan Normal University, is the Principal of Taoyuan Municipal Yung-Feng High School. He has been a Curriculum Supervisor of Senior High School Education in Department of Education, Taoyuan City Government in 2019-2020. He also majored in Guidance and Counseling (B.A.) and History (M.A.).

Hong-Fa Ho was a professor with the Department of Electrical Engineering, National Taiwan Normal University, Taipei City, Taiwan. He received the E.E. Master and Ph.D. degrees from National Taiwan University in 1987 and 1991, respectively. $\mathrm{He}$ is the president of an eye-tracking company since 2018. His major research areas include eye trackers and eye-tracking analyses.

Chang-Yi Kao is an assistant professor of the Department of Computer Science \& Information Management, Soochow University, Taipei City, Taiwan. He was a sector manager of Institute for Information Industry, and he is also an industry analyst of Asia Pacific Industrial Association (APIAA). His current research interests include intelligent system, open data, business intelligent, service experience engineering.

Article submitted 2021-02-20. Resubmitted 2021-03-21. Final acceptance 2021-03-21. Final version published as submitted by the authors. 